\title{
LES ARABES ISRAÉLIENS ET LES ÉLECTIONS A LA QUATRIÈME KNESSET ${ }^{1}$
}

\section{INTRODUCTION}

Aux élections à la quatrième Knesset (tel est le nom du Parlement de l'Etat d'Israël), le 3 novembre 1959, 7 Arabes ont été élus sur un total de 120 législateurs, répartis comme suit:

Listes arabes alliées au parti Mapaï S

Mapam

Communistes

\begin{tabular}{l} 
I \\
I \\
\hline $7^{2}$
\end{tabular}

C'est le résultat d'un tableau intéressant de participation de la population arabe en Israël ainsi que de l'influence exercée sur cette population par les partis juifs. L'étude des modalités de cette participation nous permettra aussi à connaitre les préoccupations et les attitudes politiques de la minorité arabe d'Israël. En raison du secret du vote, les possibilités de pression ou de captation perdent en efficacité, et les conditions socio-économiques ainsi que les attitudes politiques de cette minorité se réflètent avec une assez grande clarté. Chaque membre des minorités est en mesure d'influer sur le résultat des élections générales israéliennes, puisque le système électoral adopté par Israël est la représentation proportionnelle, et que le pays tout entier forme une seule circonscription électorale. ${ }^{3}$

Tout groupe représenté à la Knesset sortante, ou toute liste qui a obtenu avant les élections à la nouvelle Knesset la signature de $75^{\circ}$ adhérents, a le droit de présenter une liste de candidats, et il lui est

1 Je tiens à remercier M. le Professeur B. Akzin, de l'Université Hébraïque de Jérusalem, qui a lu cet article et a voulu bien me faire part de ses observations très utiles.

Faute de données statistiques précises, il m'a été encorc impossible de faire des recherches approfondies sur les dernières élections, à la se Knesset, tenues le is août 1961.

'Les chiffres respectifs pour les législatures précédentes étaient: 3 Arabes à la lère, 8 à la 2e, et 8 à la 3e. A la ge Knesset, le 15 août I96I, 7 députés sont entrés.

" Voir, par exemple, G. Haelling, Palestine israélienne (Paris, 1952), surtout ch. 8; N. H. Bernstein, The politics of Israel - the first decade of statehood (Princeton, 1957), surtout ch. 3 . 
affecté un symbole formé d'une ou plusieurs lettres, qui figurera sur ses bulletins dans tous les bureaux de vote du pays. Le jour des élections ont le droit de voter tous les citoyens israéliens des deux sexes qui étaient âgés de 18 ans au moins le 3 I décembre de l'année précédente. Le déroulement du scrutin est organisé d'une manière très simple: l'électeur présente sa carte d'identité; un cachet y est apposé, pour s'assurer que cet électeur ne votera qu'une fois au cours de ces élections; son nom est marqué dans la liste des électeurs inscrits à ce bureau de vote, réproduction partielle du registre électoral national. L'électeur reçoit du président du bureau une enveloppe opaque, entre dans un isoloir, où il introduit dans l'enveloppe un bulletin portant l'un des symboles de liste, colle l'enveloppe et la jette dans la fente de l'urne, devant les membres du bureau de vote. Les sièges sont répartis comme suit: après le dénombrement des suffrages dans tout le pays, sont exclues les listes ayant obtenu moins de $\mathrm{I} \%$ du total des suffrages valables; puis le total des suffrages valables est divisé par le nombre des sièges de la Knesset (1 20); on répartit les sièges en divisant par ce quotient le total des suffrages valables obtenus par chaque liste; et les sièges restant à répartir sont attribués dans l'ordre aux listes disposant du plus fort reste. 1

Ainsi la minorité arabe d'Israël peut-elle influencer considérablement les résultats nationaux des élections à la Knesset. Les Arabes avaient chaque fois l'alternative de voter pour des listes fondées sur l'appartenance communale - composées d'Arabes musulmans, chrétiens et druses - ou pour des listes juives ou mixtes, autrement dit: d'accorder leur voix à une liste locale communautaire ou à une idéologie politique et sociale déterminée.

Afin de mieux comprendre la position de la plupart des Arabes en présence de ce dilemme, il convient d'analyser brièvement d'une part leur situation particulière dans l'Etat d'Israël et d'autre part la constellation des partis politiques israéliens. La fuite de la majorité des dirigeants arabes de Palestine en 1948 a laissé la population locale sans cadres expérimentés. Cette absence s'est faite d'autant plus remarquée qu'une population arabe se vit devenir en $1948^{2}$ une minorité de quelque I 20.000 personnes, sur un total de 879.000 , au sein de l'Etat d'Israël. Cette minorité atteignait, par accroissement naturel et par le retour des réfugiés, 229.844 âmes, sur un total de

1 Voir B. Akzin, The Knesset, International Social Science Journal, tome 13, 1961, pp. 567-582.

${ }^{2}$ Central Bureau of Statistics (Jerusalem), Statistical Bulletin of Istael, part E - English summary, tome II, no. 7 , juillet 1960 , P. 413 . 
2.088.68 5 , à la fin de l'année i959. ${ }^{1}$ Seulement 58.000 vivent dans les villes, tandis que 149.000 habitent des villages et 23.000 sont des Bédouins. Les villageois sont d'habitude fidèles au chef de leur bamoula (clan), les Bédouins au chef de la tribu.

Le problème est, en effet, qu'au delà de toutes les frontières terrestres du nouvel Etat vivent des masses humaines qui ont beaucoup en commun avec les Arabes d'Israël: ils y possedènt des attaches ethniques et religieuses intimes, les I 59.000 Musulmans israéliens partout, les 23.000 Druses israéliens au Liban et en Syrie, les 48.00o Chrétiens israéliens (dont la plupart sont des Grecs catholiques et Grecs orthodoxes) au Liban et en Jordanie; et de plus des attaches familiales, ressenties avec une acuité particulière à l'égard des parents ayant émigré de l'autre côté d'une frontière bouclée ou y habitant dès avant 1948. La question de la loyauté nationale des Arabes d'Israël a pris lun aspect ambivalent, et en quelque sorte tragique, du fait que la paix n'a pas été conclue entre Israël et ses voisins arabes, et que beaucoup d'Arabes ont refusé au commencement (ce qui est peut-être naturel) de s'adapter sans heurt à leur nouvelle situation et de se résigner sincèrement à l'existence de l'Etat d'Israël.

Ce dilemme ne se pose pas seulement aux Arabes de l'Etat d'Istaël, mais aussi au gouvernement. D'une part, celui-ci s'est engagé, dans la "Déclaration de l'Indépendence» israélienne de 1948 et aussi chaque fois qu'il a entrepris de définir les lignes générales de sa politique, à faire jouir les membres des minorités d'une complète égalité. Le gouvernement était tenu d'adopter cette attitude, tant à cause de ses convictions, que parce qu'une discrimination communautaire, surtout vis-à-vis de la communauté arabe, risquait de fournir un atout dangereux aux adversaires politiques d'Israël, au Moyen Orient aussi bien qu'ailleurs. D'autre part, il fallait tenir compte des considérations de sécurité très graves que suscitait la fidélité douteuse de la minorité arabe à l'égard de l'Etat d'Israël. Or la population arabe est concentrée en grande partie le long des frontières. Les régions sensibles du point de vue militaire sont: le nord de la Galilée, près de la frontière septentrionale du pays (près de 100.000 Arabes à la fin de 1959, nombreux d'entre eux Chrétiens); le "Petit Triangle", longue et étroite bande de terrain en forme de sac, adossée au secteur centre-est de la frontière (43.800 Arabes, presque tous Musulmans); et le Néguev, au contact des frontières sud-est et sud-ouest (environ I 5.000 Arabes, tous Bédouins) ${ }^{2}$. Tout cela accentuait les craintes de voir une concentration d'éléments potentiellement ennemis. Nazareth,

1 Ibid., ibid. Les chiffres qui suivent sont arrondis.

${ }^{2}$ Selon les données des départements des affaires arabes au Ministère du Premier Ministre et au Ministère de l'Intérieur à Jérusalem. 
au coeur de la Galilée, était, au début de l'existence de l'Etat, une ville presqu'exclusivement arabe (à présent elle comprend aussi une population juive en constant accroissement). L'autre ville arabe, Chafa-Amr, est nettement arabe. C'est le cas d'ailleurs des I03 villages, tous exclusivement arabes. Dans les villes avec une petite minorité arabe - il y en a cinq: Jérusalem, Ramleh, Lydda, Haifa et Acre les Arabes étaient également rassemblés dans des blocs d'habitation presque monolithiques.

Le gouvernement militaire, dont l'autorité sur un certain nombre de régions fut réglementée en 1950, affectait - et affecte encore une partie considérable des Arabes d'Israël, près de i 50.000 sur un total de 230.000 , autrement dit environ $69 \%$. Ce sont ceux qui habitent les régions en bordure des $95 \mathrm{x}$ kilomètres de frontières terrestres d'Israël, que nous avons signalées tout à l'heure comme particulièrement sensibles. Ces régions, soumises au gouvernement militaire, sont au nombre de trois: celles de la Galilée, du "Petit Triangle» et du Néguev. Leurs résidents doivent se munir d'un laisser-passer pour en sortir ou pour y entrer (mais non pour y circuler). Les Arabes et les Druses qui habitent en dehors de ces trois régions ou qui servent dans l'armée israélienne sont dispensés de laisser-passer. Les gouverneurs militaires sont compétents à détenir et à exclure des individus sur le territoire de leur ressort. Dans certains cas, des terres appartenant à des Arabes ont été expropriées ou échangées pour des raisons de sécurité. ${ }^{1} \mathrm{Ce}$ traitement exceptionnel est exposé ici dans les détails parce qu'il a joué un grand rôle dans la propagande électorale destinée aux Arabes, ainsi que, dans une certaine mesure, dans les raisons qui les ont fait voter pour tel ou tel parti.

Le système des partis en Israël a été suffisamment étudié ${ }^{2}$ et nous pouvons donc nous passer d'en décrire les détails. Il suffira d'en retenir les lignes principales. En 1959, le centre était composé de Mapai, parti social-démocrate modéré et le plus nombreux, et des

1 Parmi les livres sur les Arabes en Israël, il faut mentionner: Z. Vilnaĩ, Les minorités en Israël (cn hébreu, Jćrusalem, 1959); Ministère des Affaires étrangères d'Israël - Division de l'Information, Les Arabes en Israël(Jérusalem, 1959, paru aussi en anglais); W. Schwarz, The Arabs in Israel (Londres, 1959). Aussi, quelques chapitres de D. Peretz, Israel and the Palestine Arabs (Washington, 1958), et H. B. Ellis, Israel and the Middle East (N.Y., 1957), pp. 186-196. Parmi les articles, voir: J. L. Teller, Israel Faces its Arab Minority Problem, Commentary (N.Y.), t. 12. no, 6, déc. 1951, pp. 551-557; Abdul Aziz Zubi, The Arab minority in Israel, New Outlook (Tel-Aviv), t. 1, no. 1, juillet 1957, pp. 14-17; J. Nantet, Le problème des minorités en Israël, Études Méditerranéennes (Paris), fasc. s, automne 1958, pp. 86-94; Ch. Solente, Attitudes israéliennes à l'égard du problème de la minorité arabe, L'Afrique et l'Asie (Paris), No. 52, 1960, 4e trimestre, pp. 29-43.

${ }^{2}$ Sur les partis en Israël voir surtout B. Akzin, The role of parties in Israeli democracy, 
"Progressistes», un petit parti libéral. La droite était divisée en "Sionistes généraux», favorables à l'entreprise privée (fusionnés depuis, en 1961, avec les "Progressistes», dans un "Parti Libéral»), et Hérout qui, tout en partageant les idées économiques des "Sionistes généraux), était voué à une politique irrédentiste et demandait une expansion au-delà des frontières actuelles. A la gauche, il y avait l'Abdoutb-Haavoda, plus nettement prolétaire que Mapaï; Mapam, dont les convictions sionistes étaient seules à l'empêcher de s'identifier avec le communisme; et les Communistes qui partageaient le programme de leurs camarades ailleurs ${ }^{1}$. Enfin, il existait trois (autrefois quatre) partis religieux - dont le "Front religieux national» était le plus important - qui tenaient surtout à obtenir le maximum d'influence de la religion juive dans les divers domaines de la vie en Israël.

L'intensité avec laquelle on s'adonne à la politique dans l'Etat d'Israël fait consacrer beaucoup d'énergie et des efforts considérables à chaque campagne électorale. La politisation profonde de la vie israélienne, avec les nombreux partis juifs qui s'y affrontent, est justement ce qui a réduit au minimum le «vote flottant» lors de chacune des quatre consultations legislatives. Selon une estimation vraisemblable, ${ }^{2}$ un électeur juif sur trois ou quatre détenait une carte de membre d'un parti; par contre, en ce qui concerne les électeurs arabes israéliens, une petite partie - quelques centaines seulement sont inscrits dans un parti. La rivalité entre les divers clans, et au sein même de chacun d'eux, a déterminé le caractère des listes arabes (qui apparaissent généralement peu avant les élections, afin de soutenir tel ou tel candidat) bien davantage que des motifs idéologiques. Il s'est trouvé des jeunes qui ont donné leurs voix à Mapam et aux Communistes, et qui ont influencé leurs familles d'en faire autant, mais la fidélité de la plupart des électeurs (et des électrices) arabes envers leurs chefs influents reste comme avant.

Cette indétermination idéologique a eu pour résultat l'augmentation du vote flottant des groupes, parmi les Arabes. Il était donc très

Journal of Politics, t. 17, no. 4, nov. 1955, pp. 507-545. Consulter aussi: M. Roshwald, Political parties and social classes in Israel, Social Research, t. 23, été 1956, pp. 199-218; T. M. Goodland, A mathematical presentation of Israel's political parties, The British Journal of Sociology, t. 8, sep. 1957, pp. 263-266; E. E. Gutmann, Some observations on politics and parties in Israel, India Quarterly (New Delhi), t. 17, janv.-mars 196r, pp. 3-29; A. Sherman, Israeli socialism and the multi-party system, The World Today (Londres), t. 17, mai 1961, pp. 217-226. Seul l'article du Professeur Akzin s'occupe, en détail, des partis arabes en Israël.

${ }^{1}$ Sur le parti communiste en Israël, voir H. Niedermeyer, Die kommunistische Partei Israels, Zeitschrift für Geopolitik (Heidelberg), t. 10, oct, 1956, Pp. 5-I0; W. Z. Laqueur, Communism and nationalism in the Middle East (2e éd., Londres, 1957), surtout pp. I $12-$ 119.

Akzin, op. cit., dans Journal of Politics, p. 523. 
important pour tous les partis d'obtenir les voix arabes - et surtout celles des chefs - car le nombre des représentants de chaque parti à la Knesset dépendait, comme nous l'avons dit, des suffrages obtenus sur le plan national. Bien plus, les citoyens arabes d'Israël ont montré qu'ils exerçaient volontiers leur droit de vote, proportionnellement même plus que les Juifs (sauf lors des élections à la Ière Knesset en 1949, quand le pays était encore en état de guerre). Aux élections à la lère Knesset $79,3 \%$ des électeurs arabes ont fait usage de leur droit de vote (contre un pourcentage général de 86,9 ); à la $2 e-85,5 \%$ (pourcentage général: 75,4 ); à la $3 \mathrm{e}-92,1 \%$ (pourcentage général: $82,8)^{1}$. Aussi une lutte acharnée et passionnée a-t-elle été livrée pour obtenir ces voix avant les élections à la $4 \mathrm{e}$ Knesset, fixées au 3 novembre 1959 .

\section{LES MINORITÉS ARABES ET LES ÉLECTIONS À LA 4e KNESSET}

Vingt-quatre listes s'étaient mises sur les rangs. Aux quatre listes des partis mentionnés plus haut, s'ajoutaient, du côté juif, des listes éphémères déposées par des mécontents ou formées suivant les pays d'origine, comme cela se passait - avec des variantes - à l'occasion des élections précédentes. Chez les Arabes, apparurent six listes spécifiquement arabes, toutes improvisées: trois d'entre elles alliées à Mapaï ("Coopération et Fraternité», "Agriculture et Développement", "Progrès et Renaissance»). Théoriquement elles s'adressaient toutes les trois à tous les Arabes d'Israël, mais pratiquement elles étaient destinées l'une à la région de Nazareth, l'autre à la Galilée occidentale et la troisième au "Petit Triangle», et l'on y avait soigneusement dosé la participation de toutes les communautés arabes: Musulmans, Chrétiens et Druses. ${ }^{2}$ Une autre liste était alliée à Abdout-Haavoda: elle portait le nom de "Parti israélien du Travail" (en arabe: al-Amal). Les deux restantes étaient indépendantes, et avaient été constituées chacune par un ex-député, à qui Mapaï n'avait plus accordé son appui pour les élections à la 4e Knesset: l'une s'intitulait "Groupe

\footnotetext{
${ }^{1}$ Selon les données du Bureau central de statistique à Jérusalem, Les résultats des élections à la ze Knesset et aux municipalités (en hébreu, Jérusalem, 1956). A la se Knesset ce sera $87 \%$, contre un pourcentage général de 81,4 . Les données sur le vote des istaéliens non-juifs se basent sur les résultats dans les villes et villages exclusivement non-juifs, où habite la grande majorité des non-juifs (par exemple, 76.214 des 86.729 non-juifs ayant le droit de vote aux élections à la ze Knesset - voir ibid.). Sur les Arabes aux élections de la lère, ze et ze Knesset, voir $G$. Weigert, dans The Jerusalem Post (Jérusalem), 10 juillet, 6 août et 12 octobre, I95 I; M. Roshwald, Les élections israéliennes de juillet 1955, Revue Française de Science Politique, t. s, oct.-déc. I955, pp. 825-830.

2 D. Peretz, Reflections on Israel's fourth parliamentary elections, Middle East Journal Washington), t. $\times_{4}$, I960, surtout pp. 19-20.
} 
indépendant des Arabes d'Israël» et l'autre "Progrès et 'Travail»" En outre, deux partis de gauche, Mapam et les Communistes, avaient mis des candidats arabes à des places "sûres» sur leur propre liste.

Nous avons déjà parlé de l'absence de personnalités dirigeantes politiques éminentes parmi les Arabes d'Israël. En conséquence, er en raison de l'absence de différences idéologiques, toutes les listes purement arabes étaient des listes improvisées, dont la constitution avait été presqu'entièrement déterminée par l'attitude des partis juifs. Les alliances entre les listes arabes et les partis juifs se font sur la base de l'appui que les députés arabes s'engagent à donner au programme général du parti juif respectif, tout en gardant la liberté de revendiquer les intérêts particuliers de la population arabe. Le parti juif, par contre, participe au financement de la propagande et essaie de donner son "patronnage» aux adhérents de la liste dans les postes publics.

Mapaï, ayant décidé pour diverses raisons de refuser son concours à deux députés arabes qui lui étaient alliés, avait l'alternative d'apporter son appui à de jeunes Arabes cultivés, ou bien aux notables plus âgés, mieux connus parmi les Arabes d'Israël. Deux facteurs semblent avoir fait pencher la balance; d'une part, l'opinion des cercles arabes qui furent consultés - l'archevêque George Hakim et son entourage pour les Grecs catholiques, le Conseil de l'Eglise orthodoxe, les autorités religieuses druses, et surtout les notables musulmans; d'autre part, l'avis de ceux qui avaient fait le décompte des voix susceptibles de se concentrer sur les candidats âgés, jouissant de prestige. C'est ainsi que l'on désigna des candidats arabes respectables, issus en plupart de familles notables (tels qu'Ahmad Kamel ad-Daher), en tenant compte, nous l'avons dit, aussi bien de leur appartenance confessionnelle que de la nécessité de les répartir judicieusement entre les diverses régions du pays; toutefois une attention particulière fut accordée à la Galilée et au "Petit Triangle", où réside la majorité des électeurs des minorités. Les deux anciens députés arabes laissés à côté par Mapaï intervinrent chacun à la tête d'une liste indépendante, et ne réussirent pas. Abdout-Haavoda mit quelques dirigeants ouvriers à la liste du "Travail». Mapam et les Communistes placèrent sur leurs listes leurs députés arabes sortants. Les autres partis diffusèrent une partie de leur propagande en arabe, pour rechercher au moins une partie des suffrages des électeurs arabes.

1 Aux élections à la se Knesset, en 1961, le nombre des listes arabes diminua: 2 listes alliées à Mapaĩ, 2 listes indépendantes. 


\section{LES PROGRAMMES}

L'étude des programmes ${ }^{1}$ nous permet de nous faire une idée non seulement des méthodes de propagande, mais aussi du caractère des diverses listes en elles-mêmes et de l'aspect sous lequel elles entendaient apparaître aux Arabes. Les trois listes arabes alliées à Mapaï publièrent des programmes assez analogues. Sous la forme de petites brochures imprimées, de 8 à 12 pages, ces programmes évoquaient à peu près les mêmes thèmes, mais dans un ordre différent. "Progrès et Renaissance", par exemple, demandait dans son programme l'extension des droits civiques des Arabes israéliens en général, et en particulier (dans l'ordre du texte) l'ouverture d'écoles convenables; l'accession des Arabes qualifiés à tous les emplois; le développement de l'artisanat et de l'industrie arabes; la solution du problème des terres arabes expropriées; l'extension des services fournis par les assurances sociales; l'élévation du niveau agricole par l'aide de l'Etat; l'augmentation des allocations aux économiquement faibles; la garantie d'un emploi pour tous et l'amélioration des conditions de travail; la réduction de la zone du gouvernement militaire à la région frontalière immédiate, en attendant sa suppression totale; la diminution des impôts; le consentement de prêts et allocation de subventions à la ville de Nazareth. La liste "Agriculture et Développement" soulignait davantage les problèmes de la jeunesse intellectuelle arabe (promesse de lui donner du travail) et la réforme de l'impôt sur le revenu. Le programme de la liste "Coopération et Fraternité" mettait plus en relief les questions de législation ouvrière (assurance obligatoire contre la maladie et contre le chômage) et la promotion de l'instruction et l'amélioration du statut des femmes par des lois adéquates.

Ces trois programmes ont le même style, malgré de légères différences entre eux, et proposent la même solution aux revendications arabes. Les chefs des trois listes (ainsi que Mapaï qui les aidait) ne pouvaient faire abstraction des plaintes arabes, surtout en ce qui concerne les restrictions que leur impose le gouvernement militaire, l'expropriation d'une partie de leurs terres pour de raisons de sécurité, la situation peu satisfaisante pour certains des diplômés de l'université qui ne réussissent pas toujours à trouver un emploi, et le poids de l'impôt sur le revenu. En faire abstraction, c'est livrer aux listes adverses une arme de propagande des plus dangereuses; promettre des réformes dans tous ces domaines aurait été ridicule, alors surtout que les représentants arabes savaient qn'il ne leur serait pas possible d'obtenir sur-le-champ des solutions satisfaisantes. La ligne de leur 1 Qui restèrent presque les mêmes, d'ailleurs, aux élections de $196 \mathrm{r}$. 
propagande consistait donc à reconnaître dans leur programme que certaines revendications étaient fondées, et à insister sur la nécessité de les satisfaire progressivement, et à proclamer que seuls les chefs de ces trois listes, en raison même de leurs attaches avec Mapaï, étaient en mesure d'amener ce parti et le gouvernement d'Israël à procéder, dans un esprit de collaboration, aux réformes nécessaires.

Le parti "Travail» avait été fondé avant les élections avec le concours de Abdout-Haavoda, sur une base fédérative, en vue d'agir parmi la population arabe. Dans son programme, il s'efforçait de se présenter aux électeurs arabes comme la contrepartie de Mapaï et des listes arabes qui lui étaient alliées. "Travail" affirmait que son programme, visant à développer la campagne pour les droits civiques des Arabes en Israël, était le premier de ce genre depuis la création de l'Etat. Ce programme visait la suppression totale du gouvernement militaire, l'émancipation des masses ouvrières et paysannes (fellahs), l'admission des travailleurs arabes à la Confédération israélienne générale de travail (Histadrout), ${ }^{1}$ l'élévation du niveau de vie des Arabes d'Israël, le développement agricole, industriel et économique, l'amélioration du statut de la femme, la création de municipalités et de conseils régionaux dans toutes les communes, le développement de la langue et de la culture arabes, la garantie de la liberté de la parole et de la presse, l'amendement de la loi sur l'expropriation des terres, l'abrogation de la loi sur les biens des emigrés, la solution du problème des réfugiés, le regroupement familial (c'est-à-dire, permission à un plus grand nombre d'Arabes vivant au-delà des frontières de rejoindre leurs familles en Israël), le relogement des Bédouins et une neutralité absolue entre l'Est et l'Ouest.

Contrairement à Mapaï et à Abdout-Haavoda, Mapam n'a pas pris l'initiative de créer des listes arabes alliées, mais a préféré de préparer conjointement une liste pour les électeurs juifs et arabes. Dans son programme figurait, comme principe de base, une égalité pour les citoyens arabes", mais dans la présentation de ce programme aux Arabes, en langue arabe, ${ }^{2}$ Mapam mettait l'accent surtout sur l'égalité, une politique fiscale plus indulgente et l'opposition aux aventures militaires. Pour plus de détail, les points suivants étaient soulignés à l'intention des populations minoritaires dans le programme de Mapam: égalité complète pour les Arabes d'Israël; abrogation totale et immédiate du gouvernement militaire; développement de l'agriculture arabe; encouragement du mouvement coopératif parmi les Arabes; garantie du plein emploi; repatriement des réfugiés arabes ou, en

1 Demande réalisée depuis, en 1960.

- Par exemple, dans l'hebdomadaire de Mapam en arabe, «al-Mirsad», 1 oct. 1959. 
cas d'impossibilité, versement d'indemnités suffisantes; regroupement familial; augmentation des salaires et réduction des impôts; suppression de contributions indirectes; allocations familiales à partir du troisième enfant et jusqu'à l'âge de seize ans; ${ }^{1}$ politique étrangère neutraliste; efforts en vue de négociations directes avec les pays arabes; neutralisation du Moyen-Orient; fin de la course aux armes dans cette région, et garantie de la souveraineté et de l'intégrité d'Israël par les Puissances; octroi irrévocable de toutes les libertés démocratiques; révision des lois sur l'état de siège.

Le programme de Mapam, dont certaines parties avaient été fréquemment soumises aux électeurs arabes avant les élections de 1959, renferme des revendications plus radicales que ceux des listes alliées à Mapaï et que celui du "Travail». Les exigences de Mapam qui portent sur l'abrogation immédiate du gouvernement militaire ainsi que sur l'égalité sociale et divers allégements économiques sont conformes aussi bien aux principes marxistes de ce parti qu'aux doléances des Arabes israéliens. Mapam va au-devant du désir des Arabes de voir revenir les réfugiés, mais, en tant que parti sioniste, admet la possibilité de les indemniser au lieu de les repatrier et adopte une attitude positive à l'égard d'une paix entre les pays arabes et Israël obtenue par des négociations directes.

Le parti communiste (appelé $M a k i$ ), de son côté, s'est efforcé dans sa propagande électorale de définir Mapaï et Mapam aux yeux des Arabes comme des partis "sionistes» et d'y apparaître par contraste le seul parti sincèrement attaché aux véritables intérêts des Arabes d'Israël. Le parti s'est empressé de diffuser son programme parmi la population juive et arabe dès la fin du mois d'août 1959. ${ }^{2}$ En voici l'essentiel: la Palestine est la patrie des deux peuples, juif et arabe, et il convient de reconnaître les justes droits des Arabes de Palestine, y compris celui des réfugiés arabes de revenir dans leur patrie et de recouvrer leurs terres; abrogation du gouvernement militaire, ce qui devrait accélerer l'établissement de la paix; rupture de tous les liens entre Israël et le camp impérialiste, et rapprochement avec les pays communistes et les Etats afro-asiatiques; suppression des privilèges accordés au capital étranger en Israël; nationalisation des concessions étrangères et des ressources naturelles; hausse des salaires et du niveau de la vie; développement des activités productrices; renforcement de l'équipement et des services sociaux; garantie d'emploi aux travailleurs; amélioration des conditions de travail; réduction

1 Aujourd'hui les allocations commencent avec le quatrieme enfant ayant moins de quatorze ans. On comprend bien l'attraction d'une telle promesse pour les familles nombreuses. 2Dans l'organe communiste de langue arabe, «al-Ittibad», 28 août x959; voir aussi ibid., 4 sept. 1959 . 
des impôts; assistance aux cultivateurs, aux professions libérales, aux petits et moyens producteurs; promulgation d'une constitution ${ }^{1}$ démocratique entrainant l'abolition de toutes les lois exceptionnelles et la protection des libertés civiques; octroi de l'égalité aux Arabes dans tous les domaines.

Ce programme n'est guère différent de ceux des partis communistes ailleurs; il repose en effet sur une utilisation habile de slogans généraux en vue de saisir l'imagination des masses. Dans la mesure où ce programme est particulièrement israélien, il ne se distingue pas beaucoup de celui de Mapam, sur les points qui touchent, dans l'un et l'autre, les Arabes. La différence ne réside pas justement dans les mots d'ordre socio-économiques, en quoi les deux programmes sont très semblables, mais dans leur position vis-à-vis du sionisme. Les Communistes désirent placer les Arabes israéliens devant l'alternative; voter pour un parti sioniste (ce qui, selon les Communistes, est contraire à leur intérêt) ou pour le parti communiste. Le programme recourt encore, au lieu d' "Israël", au terme "Palestine", qui suscite évidemment de nombreuses associations sentimentales chez les Arabes d'Israël, mais que beaucoup de Juifs israéliens qui habitaient le pays à l'époque du Mandat britannique ne peuvent lire sans mauvaise humeur. Mais ce n'est pas cela qui importe le plus, ni du reste la virulence du style. Ce qui mérite d'être précisé,c'est l'extrémisme d'une attitude qui néglige les intérêts d'Istaël, tels que la plus grande partie des habitants du pays les entend, dans l'intention de plaire aux électeurs arabes: la paix avec les Arabes est réclamée dans le programme communiste, mais sans aucune garantie pour la sécurité d'Israël; la revendication du retour des réfugiés arabes n'est atténuée par aucune condition préalable, comme par exemple la conclusion de la paix.

\section{LES MOYENS DE LA PROPAGANDE ÉCRITE}

Les programmes des divers partis furent publiés par la presse ou dans les tracts ou sous les deux formes. En effet la presse et les tracts constituèrent les principaux moyens de la propagande écrite parmi les Arabes israéliens, avant les élections à la 4e Knesset. La presse en langue arabe était déjà utilisée auparavant par les divers partis, entre une consultation électorale et la suivante. Quoique les organes de presse arabes parussent alors en moins de ro.000 exemplaires, en tout, leur influence grandissait du fait que les journaux passaient d'une main à l'autre (alors que le nombre des analphabètes avait diminué-voir ci-dessous, p. I4, note I) ou étaient lus à haute voix dans les

${ }^{1}$ L'État d'Israël n'a pas encore de constitution écrite, mais seulement des lois organiques, passées de temps à autre par la Knesset. 
cafés. En 1959, cet effort devint de plus en plus prononcé. Le jour des élections à la Knesset avaient lieu, en même temps, les élections aux institutions locales - municipalités et conseils locaux et régionaux. Mapaï, Mapam et les Communistes utilisèrent efficacement leur presse en langue arabe; Abdout-Haavoda publia un journal spécial.

Le quotidien "al-Yawm» et l'hebdomadaire "Haqiqat-al-amr», qui étaient censés servir la cause de la Fédération du travail en son ensemble, se montrèrent très proches des thèses de Mapaï à l'égard des Arabes et ne cessèrent, de diverses manières, de faire de la propagande pour les trois listes arabes alliées à Mapai. Il convient de remarquer que cette propagande s'exprimait avec modération, en comparaison avec les autres organes en arabe, et dans la plupart des cas était reléguée à la dernière page. "Ar-Rabita", organe de l'archevêque Hakim, le chef de l'église grecque-catholique (qui dispose également d'une grande influence sur les autres Chrétiens), appuyait les chefs de la liste "Progrès et Renaissance»; il leur accorda l'hospitalité de son journal pour y publier des extraits de leur programme ${ }^{1}$ et, à la veille même du scrutin, invita les Arabes à voter en masse selon leur conscience, mais de préférence pour la liste «Progrès et Renaissance", et en tout cas pas pour les Communistes! ${ }^{2}$

Abdout-Haavoda commença à publier, plus de sept mois avant les élections - depuis mars 1959 - un hebdomadaire en arabe intitulé "al-Amal" ('Travail). Sous la devise "Pour la fraternité, l'égalité et la paix", ce journal mena parmi les Arabes une propagande en faveur d'Abdout-Haavoda et de ses alliés arabes. De cet hebdomadaire parurent 35 numéros, jusqu'au 20 novembre 1959 inclus, ce qui indique clairement quel était son but; diffuser de la propagande en vue des élections à la 4e Knesset et aux conseils locaux. Cette propagande visait surtout, d'une part, à présenter l'alliance Abdout-Haavoda - "Travail" comme la seule formation permettant aux Arabes de défendre leurs propres intérêts, et, de l'autre, à polémiser avec les autres partis, notamment contre Mapai, Mapam et les Communistes. ${ }^{3}$ Contrairement aux journaux des autres partis, «al- $A$ mal" était pauvre en caricatures. 4

Mapam avait déjà un hebdomadaire, "al-Mirsad", qui servait bien sa propagande électorale parmi les Arabes à l'aide de la revue mensuelle littéraire et politique de Mapam en arabe, "al-Fajr». "Al-Mirsad" se montrait plus habile qu' "al-Amal» et recourait amplement aux caricatures. Au cours des deux mois précédant le scrutin, cet hebdo-

1 "Ar-Rabita), oct. 1959, pp. 21-23.

2 Ibid., nov. 1959, pp. I ff.

3 Par exemple, "al-Amal", 23 sept. 1959.

${ }^{4}$ Mais voir ibid., 28 oct. 1959. 
madaire intensifia sa propagande; il reproduisait des extraits de programme électoral de Mapam et lui attribuait le mérite d'une politique active de paix, d'un travail culturel parmi les Arabes, de revendications en faveur de leur égalité et de l'amélioration de leur niveau de vie et d'éducation; par contre, les autres partis étaient blâmés. ${ }^{1}$

Les Communistes se trouvaient attaqués, en 1959, tant chez les Juifs que chez les Arabes, avec plus de violence que lors des scrutins précédents. Leur position était de ce fait analogue à celle de Mapaï, également attaqué sur tous les fronts. Chez les Juifs, les Communistes étaient blâmés comme des agents d'une autre patrie; ils s'en défendaient en se tournant vers les masses ouvrières pour chercher leur appui. Par contre, chez les Arabes, les Communistes étaient considérés les chefs audacieux du mouvement national arabe à l'extérieur d'Israël; par exemple, ils se flattaient d'être les admirateurs de Gamal Abd anNasser, qui était alors populaire auprès d'une partie des Arabes d'Israël. Pendant le refroidissement temporaire dans les rapports entre Abd an-Nasser et Moscou, les Communistes prirent leurs distances à son égard et transférèrent leurs sympathies à Abd al-Karim Qassem. Cette versatilité, justement avant les élections, et surtout leur tiédeur à l'égard d'Abd an-Nasser, fournirent une puissante arme de propagande à leurs adversaires, et nous trouvons les Communistes dans le secteur arabe, avant les élections de 1959, plutôt sur la défensive.

Cette attitude se reflète dans de nombreux tracts, dans le journal communiste "al-Ittibad", paraissant en arabe à Nazareth, deux fois par semaine, ainsi que dans deux publications littéraires communistes en langue arabe, «al-Jadid" et "ad-Darb». Toutes les trois, mais surtout "al-Ittibad", menèrent l'essentiel de la campagne de presse. Les Communistes s'y présentaient comme le parti du progrès, en face des autres partis, qui étaient accusés de réaction et d'aventurisme. ${ }^{2}$ Le parti communiste, selon ses organes, était le seul à se dresser contre le gouvernement militaire, le service israélien de sécurité et les partis sionistes; il se considérait comme le porte-parole des masses, contre l'organisation des clans, et le seul parti capable d'amener le retour des réfugiés arabes. ${ }^{3}$

Ce ne furent pas seulement des partis particulièrement actifs dans le milieu arabe en vue des élections et disposant de leurs organes de presse qui ont eu recours aux tracts, mais aussi bien d'autres. Les partis qui n'avaient pas d'organe régulier en arabe utilisèrent les tracts pour agir sur l'opinion arabe, dont ils espéraient gagner quelques suffrages.

1 Par exemple, ual-Mirsad", I, Is et 22 oct. 1959.

2 Par exemple, le mensuel (ual-Jadid), aoùt I959, pP. 4-6, 58 .

"Al-Ittibad", surtout 28 août, 14 et 18 sep., 23 oct., 1959. 
Le nombre de ceux qui savent lire s'est accru considérablement parmi les Arabes dernièrement $(46,9 \% \text { en } 1957)^{1}$, ce qui a augmenté l'efficacité de la propagande par les tracts. Dans presque tous les cas, les tracts empruntent un langage et un style plus véhéments que les journaux. Leur véhémence s'accroît en octobre 1959, le dernier mois avant le scrutin; le nombre des tracts diffusés se multiplie aussi ce mois-là, et même de semaine en semaine. Il semble que la grande majorité a été distribuée en Galilée, la principale concentration de population arabe en Israël, mais, évidemment, il y en eut beaucoup aussi dans le "Petit Triangle» et un peu parmi les Bédouins du Néguev. Certains étaient imprimés, certains ronéotypés.

En somme, la propagande électorale écrite, en arabe, tant par la presse que par les tracts, a montré cette fois-ci un certain nombre de traits caractéristiques du point de vue de la forme. Le premier trait saillant est la quantité de poèmes publiés en arabe littéraire ou dans le dialecte parlé par les Arabes d'Israël. La minorité exprimait des louanges à l'égard du parti éditeur, la majorité des sarcasmes à l'égard des partis adversaires. Quelques-uns de ces poèmes étaient même mis en musique. Un second trait est la quantité encore plus grande des caricatures, déjà mentionnée plus haut, et l'âpreté de leur ton. De très nombreux tracts étaient ornés de caricatures, surtout ceux des trois listes arabes alliées à Mapaï, ainsi que les journaux de langue arabe.

\section{LA PROPAGANDE ORALE ET LA SOLLICITATION DIRECTE}

Le contact direct avec les masses, lors de la campagne électorale de 1959, se trouvait limité par "La loi sur les élections (moyens de propagande)" de 1959 qui constituait une innovation dans la vie politique d’Israël. Cette loi, adoptée par la ze Knesset le 6 juillet 1959, limitait les procédés de propagande et interdisait entre autres la propagande par projection cinématographique ou la propagande combinée avec des divertissements, y compris des numéros d'artistes, de musique, de chant, etc. ${ }^{2}$ Il va sans dire que cette réglementation frappait le secteur juif au même titre que le secteur arabe; cela explique peut-être l'abondance de la propagande écrite. Les émissions radiophoniques étaient, par rapport à la propagande dans la presse et dans les tracts, assez modérées. «La Voix d'Israël» est une station radiophonique appat-

1 Selon Central Bureau of Statistics (Jérusalem), Statistical Abstract of Israel 1959/60, tome ri, p. 343, tabl. XXXI. Le pourcentage est quelque peu accru depuis.

${ }^{2}$ Israel Government Year-book 1959/60 (1960), p. 107. La réglementation de la propagande aux élections de $196 \mathrm{r}$ fut encore plus stricte, mais seulement sur quelques points de détail techniques. 
tenant à l'Etat; aussi un temps égal fut accordé à chaque parti, plus quelques minutes calculées en proportion du nombre de sièges occupés par chaque groupe dans la Knesset sortante, pour y faire de la propagande librement, sans devoir soumettre les textes des discours à aucun contrôle préalable. Certains partis, et notamment Mapai, Mapam, les Communistes et Hérout s'adressèrent par la bouche de leurs candidats ou de leurs adhérents arabes à la population musulmane, chrétienne et druse, pour solliciter leur confiance.

Les discours et les meetings organisés par les partis furent aussi l'occasion de permettre à leurs militants de prendre fréquemment la parole: à ces meetings, annoncés simultanément par haut-parleurs, par tracts et par la voie de la presse, participèrent activement, par des discours et des mises au point adressés à la population arabe, non seulement les agents locaux du parti, mais aussi diverses personnalités arabes et juives; des ministres y prirent part aussi, quelquefois tenant leurs discours en arabe. Dans les agglomérations arabes plus importantes (surtout à Nazareth, Baqah al-Gharbiyeh, Taïbeh, Tirah, Chafa-Amr et Oum al-Fahm) et aussi auprès des Arabes de Ramleh, Lydda et Acre, et des Bédouins, de nombreuses réunions eurent lieu, la plupart au mois d'octobre I959, et tout spécialement les derniers jours de ce mois. Les arguments présentés n'avaient rien de nouveau; les promesses et les polémiques qui s'y donnèrent cours ${ }^{1}$ reproduisaient celles des journaux et des tracts; aussi n'y reviendrons-nous point ici.

Au cours de plusieurs de ces meetings furent déclamées des oeuvres de divers poètes vantant le parti organisateur et blâmant ses adversaires. ${ }^{2}$ Un phénomène encore plus intéressant était l'activité déployée parmi les femmes: Mapaï convoqua à Haïfa un congrès de femmes musulmanes, chrétiennes et druses, auquel participèrent des représentantes de nombreuses agglomérations de Galilée; Mapam organisa à Kafr-Yassif une réunion de femmes galiléennes. ${ }^{3}$ Un autre phénomène était le vif intérêt que les Arabes montrèrent cette fois pour les réunions, par rapport aux consultations antérieures; leur participation était plus active et même plus passionnée par rapport aux élections précédentes. Les meetings, réunis dans les salles ou en plein air, furent souvent violemment contradictoires. Les passions politiques s'enflammèrent plus que d'habitude et provoquèrent dans plusieurs endroits des conflits sérieux entre familles idéologiquement opposées ou rivales l'une de l'autre. Cela alla jusqu'à entraîner des coups et

1 Presse israélienne de septembre-octobre 1959, en arabe et en hébreu.

¿Voir, par exemple, «Kol-Haam» (quotidien communiste, en hébreu) 5 oct. I959.

3 Les quotidiens hébreux «Al Hamichmar», is oct. 1959, et «Davar», 26 oct. 1959. 
blessures (par exemple, à Kafr-Kanna), des déprédations (à Kafr-Qara), des rixes (à Ibelin), et la police dut intervenir. 1

Quant à la sollicitation directe (canvassing), la conduite pratiquée à l'égard des minorités était différente de celle pratiquée à l'égard des Juifs. C'est sans doute à l'occasion de la campagne électorale de 1959 qu'eut lieu pour la première fois une action assez systématique de sollicitation directe (répétée, d'ailleurs, avant les élections à la se Knesset, en 1961), au moyen de contacts écrits et oraux, chez les électeurs arabes. Ceux-ci reçurent, eux aussi, des sollicitations par écrit de la part des divers partis; ${ }^{2}$ ces lettres reproduisaient souvent les appels publiés dans la presse et les tracts ou prononcés dans les réunions publiques. Pour ce qui est de la sollicitation directe orale, qui était moins systématique qu'au sein de la population juive, il y fut procédé auprès des Arabes de plusieurs manières.

Dans le cas des listes arabes en Israël (mais non chez les Juifs), si le candidat a bien dressé ses plans, il a pris soin de s'assurer des relations adéquates bien avant l'approche de la date du scrutin - non sans prodiguer des cadeaux à beaucoup de gens, à l'occasion des mariages ou d'autres réjouissances familiales. A présent le candidat, ses parents et ses amis sont allés de maison en maison, surtout chez des personnes qu'ils connaissent, pour solliciter leur voix. Les collaborateurs du candidat l'ont assisté dans sa propagande, l'ont protégé et ont espionné les faits et gestes de ses adversaires. Dans de nombreux cas, le candidat a invité toute sorte de gens chez lui ou les a rencontrés dans des réunions chez quelqu'un de ses proches: le café a été généreusement offert, ainsi que des cigarettes et des bonbons, à tous les assistants. Cela explique peut-être l'affluence à ces réunions, presque dans tous les villages arabes. Si le candidat est député sortant, il n'a pas manqué de rappeler à chacun les services qu'il lui a rendus en faisant ses démarches dans les divers ministères. S'il est suffisamment considéré, il s'est employé à gagner le consentement des chefs de clans à engager leur "clientèle" à voter pour lui (on dit aussi qu'il leur a dispensé à cet effet des présents). Les chefs de clan ont décidé eux-mêmes, ou après avoir consulté le conseil du clan, pour qui voter ou comment répartir leurs suffrages. Généralement tout le clan a voté pour la même liste, et n'en a pas fait de mystère, dans l'espoir d'en tirer profit avant ou après les élections. D'autre part, les propagandistes des partis ont parcouru toutes les villes et tous les villages, accompagnés par des gens de l'endroit, et ont exposé et défendu dans chaque maison leur position à l'égard du scrutin. Des réunions de ce genre ont eu

${ }^{1}$ Presse israélienne, par exemple «al-Ittibad», 25 sept. 1959.

2 Presse israélienne, par exemple «Davar» et «Hérout», I nov. 1959. 
lieu notamment dans les villes et dans les grands villages, où des familles sont en rivalité ou bien où des brèches sont apparues dans la discipline au sein des familles et des clans; on se souviendra qu'en ville le scrutin est plus individuel. Dans certains cas, de petites réunions organisées ou spontanées ont eu lieu à la suite de sollicitation et, dans d'autres cas, même de grandes réunions; les représentants connus des partis, dont il a été déjà parlé, sont venus ensuite pour injecter une dose supplémentaire de propagande. Des différences sont apparues entre tel ou tel parti: Mapaï et les listes arabes alliées ont mené leur campagne parmi les Arabes sur deux plans, à la fois auprès des chefs de familles et de la jeunesse; les Communistes presque seulement auprès des jeunes; et Mapam lui aussi à peu près de cette manière, avec une intensité remarquable. Des autres listes arabes et juives se sont adressées, parmi les Arabes, surtout aux divers chefs de famille, en agrémentant de promesses leurs arguments de propagande.

\section{LA STRATÉGIE DE LA PROPAGANDE ET LES PROBLÈMES POLITIQUES}

Une comparaison entre l'attitude des différents partis, en ce qui concerne leur propagande électorale en milieu arabe, montre qu'en effet deux procédés se sont opposés: celui de Mapaï et des listes arabes alliées, qui a mis en relief les succès des autorités israéliennes (et indirectement - des gouvernements dont les positions-clés étaient tenues par des membres de Mapaï) et s'est engagé à poursuivre une amélioration progressive, mais effective; et celui de tous les autres partis, arabes et juifs, qui s'en sont pris aux négligences de Mapaï dans le secteur arabe, en promettant de leur côté des réformes. La différence entre les différents rivaux de Mapaï, dans ce secteur, était essentiellement d'intensité et de violence dans les attaques, et de "générosité» dans les promesses: tandis que les deux listes arabes indépendantes et les Communistes, et un peu moins Mapam, attaquaient furieusement Mapai, d'autres partis ont agi dans le même secteur avec plus de modération; cependant que les Communistes exigeaient l'abrogation immédiate du gouvernement militaire, la restitution de toutes les terres arabes expropriées et le repatriement de tous les réfugiés arabes, Mapam et Abdout-Haavoda - "Travail» se contentaient de soulever les mêmes revendications, mais en laissant la porte ouverte à un arrangement plus progressif de la question du retour des terres et à une indemnisation des réfugiés pour autant qu'il serait impossible de les réadmettre en Israël.

Pour la population juive, les questions économiques et nationales, lors du scrutin législatif de 1959, ont cessé de revêtir une importance aussi primordiale que lors des élections antérieures, en raison de la 
prospérité économique et de l'élévation considérable du niveau de vie de toutes les couches de la population. Sans doute les "Sionistes généraux» ont-ils continué à réclamer le soutien de l'Etat pour l'initiative privée, les "Progressistes» une libéralisation de la vie économique, et les partis de gauche l'augmentation des impôts frappant les possédants et l'allégement de la situation des économiquement faibles. Cependant ces demandes n'étaient guère mises en relief. En politique étrangère, la politique de "neutralisme occidentophile» avait gagné la sympathie de larges couches (malgré les réserves exprimées par les partis de gauche). Cela permet à comprendre le petit nombre de problèmes décisifs figurant comme enjeu des élections à la 4e Knesset (phénomène évident aussi avant les élections à la je Knesset). Toutefois un nouveau problème essentiel avait fait son apparition: la suggestion faite par les dirigeants de Mapaï de modifier le système électoral, en vue de remplacer la représentation proportionnelle par le scrutin uninominal, réforme qui se heurtait à l'opposition déclarée, et même véhémente, de tous les autres partis.

Dans le secteur arabe, ceux qui ont fixé la stratégie électorale des divers partis avaient affaire à des problèmes analogues, mais non identiques. Aussi les solutions trouvées étaient-elles différentes de celles présentées à la population juive. La prospérité économique dont a joui l'ensemble des Arabes d'Israël dans la seconde moitié de la dernière décade, ainsi que l'élévation nette du niveau de la vie de la plupart d'entre eux, a rendu plus facile à Mapai et aux listes arabes qui lui étaient alliées de solliciter la confiance des électeurs arabes et de leur promettre la poursuite progressive de l'amélioration économique. En effet nous constatons que les autres partis ont choisi comme point de litige non des problèmes du domaine économique, mais du domaine politique et civique, et encore davantage du domaine personnel et local. Tous les partis actifs en milieu arabe condamnent le gouvernement militaire, et, nous l'avons vu, réclament son abrogation totale immédiatement (les Communistes, Mapam, "Travail»); ils exigent aussi la restitution à leur propriétaire des terres expropriées (les mêmes partis). Certains d'entre eux rejettent la responsabilité de la Campagne de Suez et réclament le repatriement immédiat des réfugiés (surtout les Communistes). Pourtant, en lisant la presse et les tracts diffusés parmi les Arabes avant les élections à la $4 \mathrm{e}$ Knesset ou en entendant les discours qui animèrent les nombreux meetings organisés pendant cette période, on retirerait surtout l'impression qu'en dehors des problemes généraux de politique qui y étaient soulevés, une grande attention était portée aux questions personnelles et locales. Le sens des attaques et le style des promesses 
témoignent de la part prise dans cette campagne par les honneurs accordés à telle ou telle personnalité, jouissant d'une grande influence sur son village ou dans son clan, et la mise en relief des entreprises constructives ad boc (comme l'adduction de l'eau, l'inclusion dans le réseau électrique, la construction de routes, l'édification de maisons à bon marché) réalisées ou non - selon qu'il s'agit de louer ou blâmer révèle quelle importance les propagandistes et vraisemblablement aussi la population arabe accordaient ̀̀ ces questions personnelles ou locales. C'est d'ailleurs l'attitude caractéristique de la plupart de cette population, aussi lors des élections aux rère, 2e, ze et je Knessets.

\section{LA JOURNÉE DU SCRUTIN}

Le scrutin, le 3 novembre 1959 , se déroula dans le calme et l'ordre. Alors que, pour la ze Knesset, il y avait, dans les agglomérations nettement non-juives (c'est-à-dire sans compter les cinq villes avec une minorité arabe) 184 bureaux de vote sur un total de 2073, 1 pour la 4e Knesset il y en avait I93 sur 2408 (le nombre va s'accroítre encore pour la se Knesset - 2 I 3 sur 2558). Les électeurs votaient séparément pour la Knesset d'une part et pour les municipalités et les conseils locaux d'autre part, comme il a été déjà expliqué plus haut. Malgré la participation intense et le grand intérêt montré pour le scrutin par la population arabe, il n'y eut presque pas de bagarres, et la police ne fut alertée que dans quelques endroits pour tempérer le déchaînement des passions, charge qu'elle parvint à remplir sans effort particulier. Dans beaucoup d' agglomérations arabes, la plupart des électeurs s'acquittèrent de leur devoir dès le matin ou en tout cas avant midi. En de nombreux endroits ruraux les clans convinrent entre eux d'un arrangement, selon lequel tel clan voterait à telle heure et tel autre clan à telle autre heure. Cela permit en fait au chef de chaque clan de contrôler plus efficacement la venue aux urnes de leurs hommes et de leurs femmes et, dans de nombreux cas, de les obliger à voter selon sa volonté (en exerçant une pression morale, naturellement). Selon divers observateurs, assez rares furent ceux qui se rebellèrent, dans les villages, contre la pression des chefs de clans et de familles en ce qui concerne le scrutin; mais de tels jeunes hommes se trouvèrent quand même (et plus qu'aux scrutins précédents, cette tendance s'accrut encore, paraît-il, lors du scrutin de 1961 ).

Signalons notamment le vote des femmes, qui fut massif. Dans beaucoup d'endroits, le nombre des électrices l'emporta sur celui

${ }^{1}$ Bureau central de statistique, Les résultats à la 3 e Knesset (op. cit., 1956), p. I91, tabl. I. En plus, bien sûr, une petite partie des électeurs arabes vota aux bureaux dans les villes mixtes, où il est impossible de préciser les résultats relatifs aux Arabes. 
des électeurs. En général, les femmes arabes votèrent selon les instructions de leur mari. ${ }^{1} \mathrm{~A}$ dix-huit ans, la plupart sont déjà mariées et, dans les villages, obéissent presque sans exception aux consignes de leur époux quant au suffrage à exprimer. Les chefs de familles et de clans s'efforcèrent pour la plupart de faire voter les femmes dès le matin, afin d'éviter l'éventualité que des adversaires réussissent à troubler l'esprit des femmes avant le scrutin et à leur faire échanger les bulletins de vote que leur mari leur avait donnés. Il est vrai qu'en divers lieux, comme à Ara, avaient été organisées, par un accord spécial, des files d'attente séparées pour les femmes. Dans ces endroits, il y eut des cas où des jeunes gens parvinrent à décider leurs soeurs à voter comme ils l'entendaient, contrairement à la volonté du chef de clan. C'est là une brèche importante et significative, malgré son extension limitée, dans la pratique électorale dans les villages arabes. Dans les villes, à Nazareth et à Chafa-Amr, ainsi que dans de grands villages d'un niveau culturel élevé, tels que Taïbeh et Tirah, il arriva plus souvent (mais pas très souvent) que des femmes ont voté à leur guise. Il s'agit là surtout des femmes instruites. A Nazareth surtout, les nonnes se rendirent en foule aux urnes, en dépit de leurs habitudes, mais pour répondre à l'appel des dirigeants des églises chrétiennes locales en faveur de la lutte contre le communisme.

Vingt-cinq membres d'une tribu bédouine des environs de Nahalal, qui s'était réfugiée aux environs de Nazareth à la suite d'une vendetta arabe à laquelle ils craignaient d'être exposés, devaient, avant de voter, arranger une "soulha» (conclusion d'une trêve) de deux heures entre eux et leurs poursuivants, ménagée à cet effet par un officier de police juif. ${ }^{2}$ D'autres Bédouins furent transportés à de grandes distances jusqu'à leur bureau de vote par les soins des divers partis. Le premier bureau de vote de tout le pays qui ferma ses portes le jour du scrutin fut celui des Bédouins Arab-al-Aramcha, qui sont fixés près de la frontière libanaise, et qui participaient pour la première fois à des élections legislatives. A ceux qui leur demandaient comment ils avaient fait pour terminer les premiers ils répondirent: "La liste électorale comprenait 64 noms. Ayant constaté que tout le monde avait voté sauf quatre électeurs, nous savions que s'était fini, parce que les quatre défaillants s'étaient enfuis au Liban et n'allaient certainement pas revenir pour prendre part au vote" ${ }^{3}$.

De même qu'avant les élections à la 4e Knesset quelques accusations

1 Voir, par exemple, «al-Ittibad», 6 nov. 1959.

"Le quotidien hébreu "Haarets", s nov. 1959.

s Ibid., 17 nov. 1959. 
de pression sur les électeurs arabes avaient été formulées, ${ }^{1}$ de même après les élections furent proférées oralement et par écrit des accusations variées de pression et de promesses de portée personnelle ou locale pour telle ou telle liste. Il est difficile de savoir ce qu'il y a de vrai dans ces accusations mutuelles, peu nombreuses d'ailleurs, que les partis se sont lancés à la tête avant et après le scrutin. En tout cas il semble que ces accusations n'ont pas été frequentes, ni du reste graves; sinon les adversaires auraient tenté d'intenter des procès aux suspects. En somme, essais de pression ou d'achat de suffrages avaient été rendus malaisés, justement par la naïveté et l'ignorance de beaucoup d'électeurs arabes, vraisemblablement des vieilles couches, qui ne comprenaient qu'avec peine ce qui se passait, malgré les nombreuses explications données, et placèrent dans l'enveloppe un bulletin de chacune des vingt-quatre listes ou, voulant faire plaisir à divers partis, mirent plusieurs bulletins, un de chaque liste, dans la même enveloppe ${ }^{2}$ (ainsi leur suffrage se trouva nul dans l'un et l'autre cas). Toutefois de tels cas, nous l'avons dit, étaient rares; ils étaient probablement inexistants chez les jeunes. Ceux-là, échappant en part à l'influence patriarcale, surtout dans les villes et grands villages, votèrent assez souvent d'après leurs convictions ou leur intérêt politique, économique ou personnel. Les mêmes attendaient avec plus de curiosité que lors des scrutins précédents, tout à fait comme dans les agglomérations juives, le dépouillement des suffrages dans toutes les localités et la publication des résultats du vote au lieu de leur domicile.

\section{LES RÉSULTATS}

Aux élections à la 4e Knesset il y avait dans l'Etat d'Israël au total I.2 18.724 titulaires du droit de vote, dont $994.306(8 \mathrm{I}, 6 \%$ ) participèrent effectivement au scrutin, exprimant 969.337 suffrages valables, 3 alors qu'aux élections à la 3e Knesset, pour 1.057 .795 titulaires du droit de vote, il y avait eu $876.085(82,8 \%)$ votants et 853.219 suffrages valables. ${ }^{4}$ Le nombre des titulaires du droit de vote avait donc

1 Presse israélienne, surtout "Lamerbav» et "Kol-Haam", I oct. 1959; "Maariv», 7 oct. 1959; "Lamerhav", "Al Hamichmar" et "Kol-Haam", 8 oct. 1959; "Al Hamichmar", 13 oct. 1959; "Davar", 26 oct. 1959.

"Haarets", 17 nov. 1959.

S Statistical abstract of Israel 1959/60, p. 4I s, tab. I. Le bureau central de statistique a justement publié, Les résultats des élections à la 4 e Knesset (en hébreu, 1961), qui confirment ces données. Cette dernière publication ne détaille pas, malheureusement, le vote de chaque liste arabe (mais combine leur vote total), ce qui nous oblige de chercher des données ailleurs.

4 Bureau central de statistique, Les résultats à la ze Knesset (op. cit., 1956), tab. III. 
augmenté de plus de 160.000 , dont environ 7500 arabes ${ }^{1}$. Cet accroissement considérable semble toutefois avoir eu moins d'influence que d'autres facteurs sur les différences entre les résultats de ce scrutin et ceux du précédent. Sur le plan national les résultats principaux furent les suivants (comparés à la ze Knesset): ${ }^{2}$

Tabl. I. Progrès des partis principaux au scrutin à la 4e Knesset, 1959 (pourcentages de la totalité des suffrages valables).

\begin{tabular}{lrrr}
\multicolumn{1}{c}{ Parti } & 3e Knesset & 4e Knesset & Progrès \\
Mapai & $32,2 \%$ & $38,2 \%$ & $+6,0 \%$ \\
Hérout & $\mathbf{1 2 , 6 \%}$ & $13,5 \%$ & $+0,9 \%$ \\
"Front religieux national" & $9, \mathbf{1} \%$ & $9,9 \%$ & $+0,8 \%$ \\
Autres partis religieux juifs & $5,0 \%$ & $4,7 \%$ & $-0,3 \%$ \\
Mapam & $7,3 \%$ & $7,2 \%$ & $-0,1 \%$ \\
«Sionistes généraux" & $10,2 \%$ & $6,2 \%$ & $-4,0 \%$ \\
Abdout-Haavoda & $8,2 \%$ & $5,9 \%$ & $-\mathbf{2 , 3} \%$ \\
"Progressistes" & $4,4 \%$ & $4,6 \%$ & $+0,2 \%$ \\
Communistes & $4,5 \%$ & $2,8 \%$ & $-1,7 \%$ \\
Listes arabes & $4,9 \%$ & $4,8 \%$ & $-0,1 \%$ \\
Autres listes juives & $\mathbf{1 , 6 \%}$ & $-2,2 \%$ & $+0,6 \%$ \\
& $\mathbf{1 0 0 , 0 \%}$ & $100,0 \%$ &
\end{tabular}

Quelques groupes juifs périphériques n'atteignirent même pas I \%, pourcentage indispensable pour participer à la répartition des sièges. Leurs voix se trouvèrent ainsi éliminées définitivement de la course; cu fut le cas aussi pour la liste arabe du "Travail» et pour les deux listes arabes formées par des députés sortants laissés de côté par Mapaï.

Ces résultats nationaux se trouvèrent partiellement éclairés d'une lumière différente quand on les examine par rapport à la population arabe. Sur les 94.193 titulaires du droit de vote arabes, 84.56 I avaient voté, soit à peu près $88,4 \%$, ce qui représente $6,8 \%$ de plus que le pourcentage moyen pour tout le pays. S'il est facile d'étudier ce vote dans les agglomérations exclusivement arabes, cela exige une estimation, sinon de la divination, dans les villes à majorité juive. Mais, comme la plupart des Arabes vivent ailleurs que dans ces villes mixtes, l'approximation prudente à laquelle on se livre sur le vote des Arabes dans ces villes (en supposant qu'ils ont voté, en pourcentages, comme ceux des agglomérations nettement arabes) n'est pas de nature à mettre sérieusement en doute la vérité générale des constatations que nous allons faire. Voici, dans l'ensemble, les résultats du vote arabe:

1 Ibid., tabl. VII; le numéro exact était de 7464 .

2 Voir l'officiel Recboumot - Yalqout Hapirsoumim, no. 717, is nov. 1959, pp. 263-265. Le pourcentage - d'après le Mensuel statistique d'Israël, lère partie - statistique sociale (en hébreu), t. 10, no. II, nov. 1959, p. 601; et d'après le Bureau central de statistique, Les résultats à la 4e Knesset, tabl. II. C'est de ces ouvrages que la plupart des données qui suivent sont reproduites. 
Tabl. II Le vote arabe en Israël

$$
\text { Le parti }
$$

Mapai et les listes arabes alliées

Communistes

Mapam

Abdout-Haavoda - "Travail" (arabe)

"Front religieux national"

Hérout

"Sionistes généraux"

"Progressistes"

Autres listes arabes et juives

Total des suffrages valables des arabes

\begin{tabular}{cc} 
3e Knesset & 4e Knesset \\
$62,4 \%$ & $52,0 \%$ \\
$15,2 \%$ & $10,7 \%$ \\
$7,0 \%$ & $12,5 \%$ \\
$6,1 \%$ & $5,1 \%$ \\
$1,8 \%$ & $3,3 \%$ \\
$0,5 \%$ & $2,2 \%$ \\
$0,7 \%$ & $1,4 \%$ \\
$0,8 \%$ & $1,0 \%$ \\
$5,5 \%$ & $11,8 \%$ \\
\hline $100,0 \%$ & $100,0 \%$
\end{tabular}

Mapaï, Mapam et les Communistes restent les trois partis les plus actifs dans le secteur arabe et ceux qui y récoltent de ce fait le plus de voix: !ils ont en effet reçu, tous les trois ensemble, environ $84,6 \%$ des suffrages arabes à la 3 e Knesset et environ $75,2 \%$ de ces suffrages lors des élections à la 4e Knesset. Mais du vote arabe en 1959 ressort, d'une part, la progression de Mapam et, d'autre part, la régression de Mapai et des Communistes.

La régression de Mapaï en milieu arabe (tout en enregistrant de sensibles progrès sur le plan national) n'était pas imprévue. Etant le parti dont les chefs ont occupé, pendant les onze ans et plus de l'existence de l'Etat, les postes essentiels du gouvernement, il s'est trouvé en butte aux accusations des propagandistes de ses rivaux pour tout ce qui n'était pas au point. Les réponses données par les agents de Mapaï, sur le plan du développement économique et des services sociaux, semblent avoir moins convaincu les électeurs arabes. Ceux-ci considéraient, paraît-il, cette amélioration comme leur revenant de plein droit - au même titre qu'à leurs voisins juifs - tandis qu'ils étaient seuls à supporter le gouvernement militaire. Toutefois la régression de Mapaï parmi les Arabes s'est manifestée vraisemblablement par la diminution de ses propres voix, mais non pas, du moins pas d'une manière sensible, de celles des listes qui lui étaient alliées: celles-ci, comme lors des élections à la ze Knesset, firent élire cinq députés. Autrement dit, 5 sur 7 députés arabes à la 4 e Knesset sont rattachés à $M a p a i ̈$, et l'avis des arabes d'Israël fut encore exprimé, à la 4 e Knesset, principalement en coopération avec Mapaï. 1

La progression de Mapam n'était pas non plus le fruit du hasard.

${ }^{1}$ Ce fut aussi le cas à la ge Knesset où, en 196I, furent élus sur les listes alliées à Mapai, 4 députés (un autre fut élu sur la liste de Mapam et encore deux autres, sur la liste des Communistes). Voir aussi la brochure de H. Yaari, Que peut-on apprendre des résultats des élections à la 4 e Knesset et aux conseils locaux? (en hébreu, Tel-Aviv, 1960). Cf. aussi "Davan", s et 9 nov. 1959. 
La courbe de ses suffrages dans le secteur arabe était constamment ascendante, d'un scrutin à l'autre, mais en 1959 le parti a presque doublé le nombre de suffrages arabes pour la législature, ainsi qu'au Conseil municipal de Nazareth. En voici les causes: r.) Continuité de son action. Alors que d'autres partis ont concentré leurs efforts en milieu arabe surtout au cours des derniers mois avant les élections, Mapam a entretenu des rapports constants avec les Arabes israéliens pendant les quatre années de la troisième législature, systématiquement et grâce à un cadre d'agents dévoués. Les Ministères à la tête desquels se trouvaient des membres de Mapam (santé, développement) ont également apporté un grand soin aux affaires arabes. 2.) Les relations quotidiennes entre les villages collectivistes (kibboutsim) de Mapam et les agglomérations arabes voisines furent un facteur de compréhension mutuelle. Les kibboutsim de Mapam prodiguaient des conseils, donnaient de l'eau et fournissaient du travail aux Arabes de la région; Mapam avait pris l'initiative de fonder diverses coopératives arabes; les kibboutsim ed Mapam dans le Néguev distribuèrent du blé aux Bédouins en temps de sécheresse, en 1959. 3.) Parmi les adolescents arabes, Mapam avait créé le mouvement de "Jeunesse arabe pionnière", dans des foyers ouverts, puis, dans les kibboutsim même de Mapam. C'était là un véritable mouvement de jeunesse avec des institutions éducatives, semblable au mouvement de jeunesse juif de Mapam, mais avec l'accent mis sur les valeurs tirées de l'histoire arabe. 4.) Importance accordée à la culture arabe - par la publication d'une revue littéraire mensuelle en arabe, «al-Fajr» et la réimpression de nombreux livres excellents en arabe, tant pour les jeunes que pour les adultes. Cette attitude eut de l'effet, parait-il, sur une partie des intellectuels arabes. 5.) L'amalgame de Juifs et d'Arabes effectué sur la liste de Mapam (comme sur celle des Communistes, d'ailleurs) agit lui aussi favorablement, tant comme manifestation d'unité judéoarabe que comme manoeuvre électorale ${ }^{1}$ qui aboutit à l'élection d'un député arabe sur cette liste, justement comme à la ze Knesset (fait qui sera répété à la se Knesset, d'ailleurs).

La chute des Communistes fut leur première déroute dans le secteur arabe depuis la fondation de l'Etat d'Israël. Elle a été provoquée par diverses causes: r.) La prospérité économique des Arabes israéliens a enlevé beaucoup de sa virulence à la propagande communiste parmi eux; ainsi, les protestations communistes contre le chômage n'ont plus été prises au sérieux en 1959. 2.) La rupture entre Abd an-Nasser et les Communistes, peu de temps avant le scrutin, eut aussi son effet. Il semble qu'un nombre d'Arabes israéliens, sympathisants du natio-

1 Voir aussi "Davar", 9 nov. 1959. "Al Hamichmar", 5, 6 et 1o nov. 1959, et surtout l'article de A. Kapelyouk, ibid., I3 nov. I959. 
nalisme arabe sous sa forme nassérienne, aient trouvé chez les Communistes ou les cercles de tendance analogue un foyer de mécontentement. Certains de ceux-là furent déçus par le soutien acordé par les Communistes israéliens à Qassem. le maître de l'Irak, contre Abd anNasser, par ce qu'on considérait comme les ordres de Moscou. 3.) L' opposition aux Communistes, notamment auprès de cette partie des Musulmans d'Israël qui constitue le vote flottant, fut alimentée par des scandales antireligieux, comme le déchirement de livres du Coran, attribué - à tort ou à raison - aux Communistes irakiens. Ces attitudes sont confirmées d'ailleurs, par l'échec encore plus sévère des Communistes, en 1959, aux conseils municipaux et locaux. ${ }^{1}$ En outre, la majorité des suffrages obtenus par les Communistes en 1959 venait vraisemblablement des éléments qui leur sont inébranlablement attachés, les Chrétiens et surtout les Grecs orthodoxes, peut-être en raison des liens historiques et religieux qui les rapprochent de la Russie. En tout cas, la représentation des Communistes à la $4 \mathrm{e}$ Knesset tomba de 6 à 3 députés, dont un seul Arabe (au lieu de deux Arabes à la ze Knesset) ${ }^{2}$.

Il est moins aisé d'analyser le vote des Arabes en faveur de ces partis juifs, qui n'avaient que peu de rapports avec la population arabe en Israël, ainsi que leur vote en faveur des listes arabes.

On ne peut pas résoudre le problème en tenant compte ni des suffrages fantaisistes ou erronés, ni de rares occasions où l'on avait peut-être fait des promesses tentantes à certains de ces électeurs. La diversité du vote dans les villages arabes et les campements bédouins s'explique mieux par la tendance des Arabes de donner leurs suffrages à des listes juives ou judéo-arabes plutôt qu'à des listes purement arabes, tout en cherchant, dans la population juive, des éléments avec lesquels ils avaient des intérêts communs. L'on peut en voir un exemple, pour la première fois dans l'histoire de ce parti, d'un candidat

${ }^{1}$ Recboumot - Yalqout Hapirsoumim, no. 721, 30 nov., I959, pp. 325-363, et no. 723, 4 déc. I959, pp. 389-496.

2 Kapelyouk, op. cit., "Davar", s nov. 1959. "Hamodia", 6 nov. 1959. "Al-Ittihad", 10 nov. I959. L'éloignement manifesté par une partie des arabes, lors du scrutin à la $4 \mathrm{e}$ Knesset, à l'égard des Communistes, qui paraissait alors significatif, ne fut que temporaire. L'extrémisme de la propagande du parti communiste, lors du scrutin à la ge Knesset, a attiré une partie des Arabes qui avaient soutenu, en 1959, d'autres partis, ainsi que des jeunes Arabes qui votèrent, en I96I, pour la première fois. Le vote communiste des Arabes, en I $96 \mathrm{r}$, doubla à peu près. Selon des données officielles manuscrites, il y avait, en $1961,17.287$ voix communistes sur un total de 76.918 suffrages valables dans les localités nettement arabes, c'est-à-dire vers $22,5 \%$ - contre $15,2 \%$ à la $3 \mathrm{e}$ Knesset et $10,7 \%$ à la $4 \mathrm{e}$ (vide supra, Tabl. II). Ce furent les listes arabes indépendantes, particulièrement, qui perdirent une partie de leurs votes arabes. Les alliances des Arabes aux partis juifs continuèrent, en lignes générales et, autrement, les résultats du vote arabe, grosso modo, ne sont pas différents de ceux de 1959. 
arabe sur la liste des "Progressistes" (toujours pas à une place "sûre»). C'est ainsi que s'expliquent aussi, par exemple, les voix accordées par quelques Druses à Hérout; et il se peut fort bien qu'il y ait eu des Arabes dont les revendications correspondaient à celles des "Sionistes généraux" en faveur de l'encouragement de l'initiative privée. Il va sans dire qu'on ne peut pas encore voir dans les quelques milliers de voix accordées aux partis juifs, pas plus que lors des élections à la ze Knesset, une révolution dans l'opinion publique chez les Arabes d'Israël. En fait les pourcentages ont changé trop légèrement par rapport aux scrutins précédents (et d'ailleurs ont varié de nouveau aux élections à la se Knesset) pour avoir une signification profonde.

Les listes des Arabes ont obtenu en tout, aux élections à la $4 \mathrm{e}$ Knesset, 46.I9I suffrages valables sur un total de 969.337 suffrages valables, ${ }^{1}$ c'est-à-dire près de $4,8 \%$ (contre $3 \%$ la rère Knesset, $4,7 \%$ à la $2 \mathrm{e}$, et 4,9 à la $3 \mathrm{e}^{2}$ ). Il n'y a pas de doute que seuls les Arabes ont voté pour ces listes. Quand-même, il est difficile de déterminer exactement le pourcentage des suffrages valables exprimés par les électeurs arabes sur le total des suffrages valables enregistrés lors du scrutin à la 4e Knesset. Les suffrages valables dénombrés dans les agglomérations non-juives ont atteint $7,4 \%$ du total des suffrages valables, ${ }^{3}$ et l'on peut supposer qu'en comptant les suffrages valables des Arabes des villes à minorité arabe, le pourcentage des suffrages valables exprimés par les électeurs arabes au scrutin pour le $4 \mathrm{e}$ Knesset monte approximativement à $8,2 \%$ du total des suffrages valables. Il en résulte que les Arabes ont donné plus de $41 \%$ de leurs voix à des listes autres que purement arabes. ${ }^{4} \mathrm{De}$ ce point de vue il est intéressant d'étudier la répartition des suffrages entre les partis dans les agglomérations nettement non-juives: villes arabes, grands villages (plus de 2000 âmes), petits villages, et tribus bédouines.

\footnotetext{
'Recboumot - Yalqout Hapirsoumim, no. 717, is nov. 1959, p. 263.

${ }^{2}$ D'après le Bureau central de statistique, Les résultats à la $4 \mathrm{e}$ Knesset (op. cit., 196I), tabl. II. A la se Knesset, ce fut 35.376 suffrages valables sur un total de 1.006 .964 suffrages valables, c'est-à-dire, 3,5\% - voir Recboumot - Yalqout Hapirsoumim, no. 869, 24 août 1961, p. 1937.

- Yaari, op. cit., p. I9. Les chiffres du bureau central de statistique à Jérusalem confirment ces calculs. Le pourcentage ne changea pas, ou presque, aux élections à la se Knesset.

- Un résumé ronétypé du département arabe de Mapai, basé sur observations-sur-place dans les agglomérations arabes et judéo-arabes, arrive à un total de 81.764 , c'est-à-dire, environ $8,4 \%$ du total des suffrages valables. Selon le Bureau central de statistique, Les résultats à la 4e Knesset, tabl. XVII, ils avaient donné $41,4 \%$ à des listes autres que purement arabes.
} 
Tabl. III 1

A. Répartition des votes ct des suffrages aux agglomérations exclusivement arabes, I959.

Types d'agglomération

Villes arabes (Nazareth, Chafa-Amr)

Grands villages arabes

Petits villages arabes

Tribus bédouines (dans tout le pays)
Electeurs

$\begin{array}{r}13747 \\ 37492 \\ 24131 \\ 9191 \\ \hline 84561\end{array}$

Voix

11980

33089

22010

7318

74397
Suffrages valables

11080

31621

21460

7018

71179

B. Répartition des suffrages valables dans les agglomérations exclusivement arabes, par les partis, 1959

\section{Parti}

Mapaĩ

"Front religieux national"

Autres partis religieux juifs

Hérout

Mapam

"Progressistes"

"Sionistes généraux"

Communistes

Abdout-Haavoda

Les $s$ listes des arabes

Autres listes (juives)

Total des suffrages

\begin{tabular}{rrccr}
$\begin{array}{r}\text { Villes } \\
\text { arabes }\end{array}$ & $\begin{array}{c}\text { Grands } \\
\text { Villages }\end{array}$ & $\begin{array}{c}\text { Petits } \\
\text { Villages }\end{array}$ & $\begin{array}{c}\text { Tribus } \\
\text { bédouines }\end{array}$ & $\begin{array}{r}\text { Total } \\
469\end{array}$ \\
458 & 1560 & 734 & 3221 \\
196 & 1467 & 878 & 59 & 2600 \\
18 & 46 & 24 & 45 & 133 \\
108 & 718 & 594 & 106 & 1526 \\
1232 & 3327 & 3445 & 2119 & 10123 \\
108 & 491 & 101 & 130 & 830 \\
30 & 631 & 331 & 64 & 1056 \\
2950 & 3965 & 1096 & 60 & 8071 \\
79 & 351 & 113 & 83 & 626 \\
5742 & 19837 & 13121 & 3264 & 41964 \\
148 & 330 & 197 & 354 & 1029 \\
\hline 11080 & 31621 & 21460 & 7018 & 71179
\end{tabular}

Si dans les trois premières catégories, la majorité des voix des arabes a été accordée aux diverses listes arabes, les tribus bédouines ont donné 3754 suffrages valables sur $7018(53,5 \%)$ aux listes juives et judéo-arabes; sur ces 3754 suffrages valables, 2853 sont allés à Mapaï et à Mapam, et seulement environ 900 à toutes les autres listes juives et judéo-arabes. Cela peut fournir une preuve, peut-être, que les Bédouins d'Israël sont éloignés de la vie publique arabe et de ses dispositions réservées à l'égard de l'Etat d'Israël (ainsi, les Communistes n'ont recueilli, chez toutes les tribus bédouines, que 60 suffrages valables - ce qui se répète à peu près en $196 \mathrm{I}$, quand les Bédouins donnèrent 217 sur $816_{2}$ suffrages valables aux Communistes) et se sont résignés à soutenir les autorités juives d'Israël. En tout cas, la nouveauté essentielle dans le vote de tous les habitants arabes d'Israël réside dans la dispersion des suffrages dans beaucoup de sens. Il est intéressant de constater que, selon tous les indices, Mapam a

\footnotetext{
' Pour les scrutins antérieurs, il n'y a pas de données séparées pour les villages et les tribus bédouines.
} 
bénéficié seulement d'une partie des voix perdues par Mapaï et les Communistes, tandis que d'autres étaient acquises par d'autres listes juives. Dans les agglomérations nettement non-juives, les principales listes juives et judéo-arabes ont obtenu le pourcentage suivant de leurs suffrages valables: ${ }^{1}$

Tabl. IV. Pourcentage des suffrages valables des Arabes par rapport aux suffrages valables ( $100 \%$ ) obtenus par chaque parti en 1959

$\begin{array}{lc}\text { Communistes } & 29 \% \\ \text { Mapam } & 14 \%^{3} \\ \text { Abdout-Haavoda } & 3 \% \\ \text { "Front religieux national" } & 3 \% \\ \text { "Sionistes généraux» } & 2 \% \\ \text { "Progressistes" } & 2 \% \\ \text { Mapai } & 1 \% \\ \text { Héraut } & 1 \% \\ \text { Autres partis religieux juifs } & 1 \% \text { (ou moins) }\end{array}$

Le tableau s'éclaire davantage si l'on examine la répartition des voix dans les différentes agglomérations exclusivement non-juives. Nazareth est le foyer de la vie arabe en Galilée et la plus grande agglomération arabe d'Israël avec ses 25.000 habitants environ. Presque tous les juifs domiciliés à Nazareth résident dans le quartier suburbain de Kiryat-Notsrat et ont voté dans des bureaux séparés. Les données ci-dessous se rapportent donc exclusivement aux suffrages des Arabes donnés respectivement aux listes arabes et aux listes juives et judéo-arabes au scrutin à la 4 e Knesset. Nazareth comptait alors 10.830 électeurs arabes. Il y eut 9296 votants. Les suffrages valables, 8546 au total, se répartissaient comme suit: ${ }^{4}$

\footnotetext{
1 Yaari, op. cit., p. 20.

2 C'est évident qu'une grande partie des adhérents des Communistes se trouvent parmi les Arabes. Ceux-là reçurent en I 959 seulement $8,2 \%$, approximativement, du total des suffrages valables, comme il a été démontré plus haut, mais $29 \%$ des suffrages valables exprimés pour le parti communiste furent des voix d'Arabes. Cette prépondérance proportionelle du vote arabe pour les Communistes - évidente malgré leur perte de voix se manifesta encore plus clairement au scrutin à la se Knesset, en r 96r, quand̀ à peu près $46 \%$ des suffrages valables exprimés pour le parti communiste furent des voix d'Atabes (selon des données non-officielles, 19.308 de la totalité des 42.1 II suffrages valables obtenus par ce parti dans tout le pays).

${ }^{3}$ Cette proportion si élevée est due aussi à la perte de voix parmi les électeurs juifs, lors du scrutin législatif de 1959 .

- Bureau central de statistique, Les résultats à la 4 e Knesset, tabl. IV., données complétées pour les listes arabes selon "Ar-Rabitc" de nov. 1959, pp. I5-16, et Yaari, op. cit. Le vote communiste excepté, la division des voix resta presque la même lors du scrutin à la se Knesset aussi.
} 
Tabl. V. Répartition des suffrages valables arabes à Nazarreth, 1959

a. Listes arabes

"Progrès et Renaissance"

"Groupe indépendant des arabes

d'Israël»

"Coopération et Fraternité»

"Travail"

"Progrès et Travail"

"Agriculture et Développement" b. Listes juives et judéo-arabes

\begin{tabular}{rlr}
2352 & Communistes & 2397 \\
& Mapam & 1200 \\
952 & Mapai & 453 \\
336 & "Front religieux national» & 185 \\
119 & "Progressistes" & 92 \\
102 & Abdout-Haavoda & 79 \\
44 & Hérout & 59 \\
& "Sionistes généraux" & 29 \\
& Autres partis religieux juifs & 16 \\
& Autres listes (juives) & 131 \\
\hline 3905 & & 4641
\end{tabular}

Au total: 8546

Il ressort de ce tableau que, même à Nazareth, les listes juives et judéo-arabes ont obtenu au total plus de voix que les listes arabes, et celà malgré la campagne de propagande contre les partis juifs, taxés de «sionistes» par les listes exclusivement arabes.

La dispersion des voix est assez nette aussi dans d'autres localités et permet de tirer une leçon supplémentaire du scrutin. Prenons par exemple, entre beaucoup d'autres, les suffrages valables exprimés par les habitants de deux agglomérations importantes du "Petit Triangle", 'Tirah et Taïbeh, très proches l'une de l'autre tant géographiquement que par beaucoup de leurs problèmes. A Taïbeh, village d'à peu près 7 roo habitants, il y avait 318 I électeurs, sur lesquels il y eut 2875 votants et 275 I suffrages valables. A Tirah, qui compte près de 5300 habitants, les électeurs etaient 2330 , les votants 1586 et les suffrages valables 1536 .

Tabl. VI. Répartition des suffrages valables à Taỉbeh et à Tirah, I959

La liste

Mapai

"Front religieux national"

Autres listes religieuses juives

Hérout

Mapam

"Progressistes"

"Sionistes généraux»

Communistes

Abdout-Haavoda

Autres listes (juives)

"Progrès et Renaissance"

"Groupe indépendant des arabes d'Israël"

"Coopération et Fraternité"

"Travail"

\begin{tabular}{rr} 
Taïbeh & Tirah \\
84 & 4 \\
1 & 315 \\
1 & - \\
8 & 49 \\
171 & 329 \\
52 & 17 \\
34 & 5 \\
694 & 375 \\
4 & - \\
48 & 33 \\
- & 2 \\
375 & 15 \\
1 & 2 \\
321 & 7 \\
21 & 4 \\
936 & 379 \\
\hline 2751 & 1536
\end{tabular}


Du tableau ci-dessus il ressort qu'il y a des différences assez grandes dans la répartition des suffrages valables. Ces différences entre deux agglomérations voisines ne sont pas fortuites, et des influences locales ont joué un grand rôle. Taïbeh est un village qui a plus d'intellectuels et qui a bénéficie plus que Tirah du régime israélien. C'est vraisemblablement en raison de cette situation que beaucoup plus de gens y ont voté pour Mapaï et les «Progressistes»-constamment partis du gouvernement - qu'à Tirah, et il en est de même pour les listes arabes alliées à Mapaï (comme il est particulièrement net en ce qui concerne les voix accordées à la liste "Agriculture et Développement»). Par contre à Tirah, malgré le petit nombre d'habitants relativement à Taïbeh, davantage de suffrages valables qu'à Taïbeh ont été accordés aux partis d'opposition comme Mapam et Hérout, et même le «Front religieux national» (qui avait mené, au cours de cette campagne électorale, une lutte acharnée contre Mapaï). Bien que les Communistes aient reçu à Taïbeh plus de suffrages valables qu'à Tirah, le pourcentage du total des suffrages valables y est néanmoins inférieur: $22 \%$ à Taïbeh contre $25 \%$ à Tirah; bien plus, si l'on compare ces résultats à ceux obtenus par les Communistes dans ces deux villages aux élections à la ze Knesset, on constate que ce parti avait recueilli alors $4 \mathrm{r} \%$ des voix à Taïbeh et seulement $10 \%$ à Tirah $^{1}$ (autrement dit: aux élections à la $4 \mathrm{e}$ Knesset, les Communistes ont fait une brusque chute en pourcentage à Taïbeh, tandis qu'ils montaient tout aussi brusquement à Tirah). ${ }^{2}$

La "palette" des résultats, si différente à Taïbeh et à Tirah, devient encore plus nuancée si on les compare à ceux d'autres agglomérations du "Petit Triangle" et au total des résultats dans ce secteur. Cela se vérifie également en ce qui concerne le vote des Arabes dans leurs agglomérations de la Galilée et du Néguev, et probablement aussi dans les villes avec une minorité arabe. Même la tendance de Mapam à y progresser n'était pas générale (ce parti ayant baissé en Galilée occidentale par rapport aux élections à la ze Knesset), ni celle des Communistes à reculer.

La perspective religieuse ou communautaire a joué également un rôle important dans les résultats du scrutin des populations minoritaires. L'appartenance à une communauté n'a pas ici un poids aussi décisif qu'aux élections parlementaires libanaises, par exemple, ${ }^{3}$ mais son influence n'est nullement négligeable. Nous avons déjà

1 Bureau central de statistique, Les résultats à la ze Knesset, appendice I, p. 14r.

${ }^{2}$ Les tendances ne changèrent pas visiblement lors des élections à la ge Knesset, excepté l'accroissement du vote communiste.

3 Voir des détails dans mon article, Elections in Lebanon, The Western Political Quarterly, t. I4, no. I, mars I96I, Pp. I 20-147. 
mentionné plus haut l'attention usuelle portée à l'appartenance communautaire au moment de la composition des listes, et surtout dans les considérations qui ont présidé au choix des têtes de listes occupant des rangs "sûrs». La liste "Agriculture et Développement" était menée par des Musulmans; il n'est pas étonnant que, dans les localités du "Petit Triangle», habitées presqu' exclusivement par des Musulmans, cette liste ait obtenu une majorité écrasante sur toutes les autres ensemble. ${ }^{1}$ Un autre exemple édifiant est fourni par l'introduction de Druses en bonne place à la tête de la liste "Coopération et Fraternité" (première place) et de la liste "Agriculture et Développement" (deuxième place). Dans chacune des agglomérations de Galilée dont la population est composée en grande majorité de Druses, ces deux listes ont recueilli toutes les voix, ou presque, alors que les autres listes exclusivement arabes n'obtenaient en général que très peu de suffrages ${ }^{2}$ (les listes juives et judéo-arabes en recueillaient tout de même un nombre non négligeable). L'analyse du vote des Chrétiens d'Israël est plus délicate; pourtant la répartition des suffrages valables à Nazareth (Tabl. $\mathrm{V}$ ci-dessus) nous enseigne que la liste "Progrès et Renaissance», la seule des listes purement arabes où un Chrétien figurait à une place "sûre" (la deuxième), a obtenu dans cette ville à elle seule un total de 2352 voix contre I 553 à toutes les autres ensemble!

\section{CONCLUSION}

Tout ce que nous venons de dire montre qu'il est difficile de tirer des conclusions générales au sujet de la participation des Arabes aux élections à la $4 \mathrm{e}$ Knesset. Il semble toutefois que leur maturité politique s'est affermie quelque peu en matière de participation à un scrutin parlementaire. Cela ne ressort pas justement du petit nombre des abstentions parmi eux, phénomène commun à toutes les élections à la Knesset et dû en partie à la pression morale exercée par les chefs des clans dans les villages et les campements des Bédouins. On pense surtout d'une part à leur vote contre Mapaï: une partie des Arabes israéliens est parvenue à la conclusion qu'en démocratie il est possible de voter sans inconvénient contre le parti au pouvoir; même plus, pour la première fois, ils donnèrent des milliers de voix aux listes arabes indépendantes, formées (on se souvient) par des députés

1 Chiffres selon le résumé du département arabe de Mapaí, op. cit.

2 Ibid. Une partie des voix fut exprimée pour la liste arabe indépendante de Khneifes, aussi un Druse - ce qui démontre, une fois de plus, l'importance de l'appartenance communautaire dans le vote des arabes en Israël. 
sortants de Mapaï - phénomène qui se répète lors des élections à la se Knesset. D'autre part, on se souvient du vif intérêt qu'ils prirent aux élections, dans leurs moindres détails, dans les villes, villages et campements bédouins et l'anxiété avec laquelle beaucoup d'entre eux attendirent les résultats de ces élections. 1

En face de ces progrès en maturité politique que révèle l'attitude arabe envers les élections à la Knesset, il convient de placer l'importance considérable encore attribuée par les Arabes en Israël aux problèmes personnels, locaux et communautaires, surtout dans les villages arabes et les campements bédouins de la Galilée et du Néguev (dans une certaine mesure aussi parmi la population urbaine de Nazareth), cause d'un opportunisme politique qui s'est exprimé par toute sorte de liens noués avec des partis grands et petits, arabes, judéoarabes et juifs, par suite de calculs intéressés qui rejetaient dans l'ombre l'attitude idéologique. Beaucoup des électeurs arabes attendent sans doute des avantages très précis du député de la Knesset à l'élection duquel ils ont contribué, particulièrement dans les affaires se rapportant à leur vie quotidienne. Un localisme opportuniste s'est trouvé encouragé par la domination quasi-féodale des chefs de clan et des chefs de tribus bédouines sur les membres de leur familles, hommes comme femmes. Par contre, les considérations politiques et idéologiques, chez beaucoup d'électeurs arabes dans les villes et chez les intellectuels de la jeune génération dans les villages arabes, ont provoqué un dépassement du cadre des préoccupations locales et présagent de nouveaux progrès de la maturité politique au sein des Arabes de l'Etat d'Israël.

2 Vide supra, p. 25, note 2. 